\section{Peak oil is affecting the economy already}

James Murray and David King sound the alarm in pointing out that oil's tipping point has passed (Nature 481, 433-435; 2012). The days of being able to produce oil cheaply and easily are over, and the economic effects are upon us. We believe that the 'peak oil' issue is as important as climate change, and more urgent. We call for peak oil to be considered more seriously as a subject of peer-reviewed research.

Economic growth began to stall at around the same time as conventional oil production in 2005. Oil-exporting nations are consuming more of their own output every year, reducing availability for the rest of the world. Yet importers who rely on oil exports include some of the world's largest economies.

The energy return on investment for oil is declining globally. There is now a growing body of research exploring the connections between financial and energy returns on oil investment, and economic health as a whole.

David J. Murphy* Northern Illinois University, DeKalb, USA. djmurphy@niu.edu ${ }^{*}$ On behalf of 8 co-signatories (see go.nature.com/qlcack for a full list).

\section{Turing: keep his work in perspective}

In a cascade of plaudits, George Dyson, Sydney Brenner and Barry Cooper each suggest that Alan Turing's bridging of logic and machines laid the foundation for digital computers, built in the 1940s under John von Neumann (Nature 482, 459-460, 461 and $465 ; 2012$ ).

Turing and von Neumann are both heroes of mine. But, in essence, Turing's famous 1936 paper on incomputability was merely an elegant rephrasing and reuse of mathematician Kurt Gödel's 1931 results and techniques. Gödel devised a more cumbersome, integerbased language to describe a universal algorithmic theoremprover, which allowed him to identify the fundamental limits of mathematics and provability.

Neither did Turing's paper have any impact on the construction of the first program-controlled universal (and digital) computer: that was built in Berlin by Konrad Zuse in 1935-41, at least 3 years before anyone else's. Zuse's 1936 patent application mentioned an architecture like that of von Neumann's (which von Neumann described in 1945), with programs and data that could be modified in storage. Computing firm IBM was well aware of these breakthroughs and funded Zuse's 1946 start-up through an option on his patents. Jürgen Schmidhuber Dalle Molle Institute for Artificial Intelligence (IDSIA), University of Lugano; and SUPSI, MannoLugano, Switzerland. juergen@idsia.ch

\section{Turing: a formal clash of codes}

Sydney Brenner argues that cells and living organisms are good examples of Turing and von Neumann machines (Nature 482, 461; 2012). But the nature of living matter cannot be properly accommodated within such a theoretical framework.

This is because the language that codes machine programs is not compatible with that of the genetic code. Languages controlling Turing and von Neumann machines are formal algorithms, in which syntax determines meaning independently of context. Gene expression depends on environmental context, however, so cannot be similarly treated as a formal language.

Syntax in DNA may convey different and even contradictory meanings, depending on the cellular agents that exploit the coded information according to their respective situations. Guenther Witzany TelosPhilosophische Praxis, Bürmoos, Austria.

František Baluška Institute of Cellular and Molecular Botany, University of Bonn, Germany. baluska@uni-bonn.de

\section{The case for brain imaging technology}

Olivier Oullier questions the commercial and judicial use of brain-scan technology to predict or judge human behaviour (Nature 483, 7; 2012). His arguments undermine a major driver of academic funding and research - its potential for commercial application. Moreover, banning the commercial use of neuroimaging could encourage government interference in the development of a promising and widely applicable tool.

Society demands benefits in return for investment in scientific research. Universities are expected to be entrepreneurial and to collaborate with industry, promote spin-offs and capitalize on intellectual property.

An emerging technology should be judged on its specificity, sensitivity and predictive value. Neuroimaging results must be assessed in their specific context, and not broadly dismissed. Functional magnetic resonance imaging used to measure motivation in response to health campaigns, for example, was found to have greater predictive value than self-reported intentions (E. B. Falk et al. J. Neurosci. 30, 8421-8424; 2010).

The technique is also able to identify paedophilial inclinations with 95\% accuracy (J. Ponseti et al. Arch. Gen. Psychiatry 69, 187-194; 2012). Careful investigation will establish whether or not such findings can one day be used as evidence in court.

Bernd Weber ${ }^{\star}$ Center for Economics and Neuroscience,
University of Bonn; and Department of Epileptology, University Hospital of Bonn, Germany. bernd.weber@ukb.uni-bonn.de ${ }^{*}$ On behalf of 13 co-authors; competing financial interests declared (go.nature.com/9dh9e2).

\section{True value of climate fund's contribution}

Edward Barbier grossly underestimates the Adaptation Fund's contribution to sustainable development (Nature 483, $30 ; 2012)$. The fund has so far received US\$273 million and committed $\$ 109$ million (see go.nature.com/sgkgr8), not $\$ 12.6$ million as quoted.

The Adaptation Fund is supported by a carbon market, one of the innovative revenue models Barbier mentions. Under the Clean Development Mechanism of the United Nations Framework Convention on Climate Change, developed countries can trade carbon credits generated by sponsoring emissions-reduction projects in developing countries, helping them to meet their emissions targets under the Kyoto Protocol.

Of the revenue generated by these transactions, $2 \%$ goes to the Adaptation Fund for programmes to help developing countries adapt to climate change. These tackle such problems as coastal erosion from sea-level rise, floods from glacial melt and droughtinduced falls in crop yields. By January 2012, the fund had spent $\$ 30.14$ million on such projects.

The carbon market is shrinking because of the global financial crisis and uncertainties over the scale of demand for emissionsreduction credits. However, the Adaptation Fund's structure means it can also accept funds from governments, the private sector and individuals.

Marcia Levaggi Adaptation Fund Board Secretariat, Global Environment Facility, Washington DC, USA. mlevaggi@thegef.org 